\title{
Determination of the skip force effect on guides in mine shaft
}

\author{
Mikhail Nikolaitchik ${ }^{1^{*}}$ \\ ${ }^{1}$ Belarussian State University, Department of Theoretical and Applied Mechanics, 4 Nezavisimosti Ave., \\ 220030 Minsk, Belarus
}

\begin{abstract}
An analytical solution is presented to the problem of determining the force effect of lifting vessel (skip) on guides during its movement in the mine shaft. Forces values are obtained using acceleration data from sensors of motion smoothness through monitoring system. The technique developed allows to determine skip force effect on guides along all axes of horizontal coordinate system. A transition from a force to impulse action is provided. The interrelation of force action surges with guides profile deviations is analyzed. The results of this study can be widely used to identify the areas in the mine shaft where emergency could potentially occur.
\end{abstract}

\section{Introduction}

The problem of determining skip force effect on guides is relevant and has not been solved yet. The determination of the skip force effect on guides in real time which can be used in development of special approaches and technologies for preventing emergencies is of particular interest.

Nowadays, a number of researchers are engaged in skip dynamics modeling problem. There are many approaches for solving this problem. So in [1], an analytical solution to the problem of oscillation of a two-mass system was considered. The aim of this study was to reduce the dynamic loads arising in certain modes of skip motion which leads to the occurrence of large oscillations of the lifting vessel. In paper [2], a relationship between the contact interaction of skip with guides and the surfaces of the guides curvature increase is set. The authors of [3] carry out finite element analysis of skip motion taking into account the aerodynamic interaction of the loaded skip and the counterweight skip. As a result, in this paper and previous paper of the same authors [4], the conclusion about the optimal gap between skip has been made. Also, it was noted that the influence of the Coriolis force is insignificant in the model under consideration in comparison with the aerodynamic interaction force of skips. Paper [5] is devoted to the development of the optimal design of buntons that satisfy conditions of strength taking into account force impact from side of skip. The authors of [6] carry out a finite element modelling of the lifting vessel motion taking into account the irregularities of the guides profile. In [7], the influence of fretting on the durability of the hoisting rope taking into account the value of the contact interaction

\footnotetext{
* Corresponding author: nikolaitchik.m@gmail.com
} 
between the rope and the sheave is determined. In works $[8,9]$, an analytical assessment of rope fatigue is made. A number of works $[10-12]$ are also devoted to the assessment of the processes occurring in the hoisting rope during the movement of the skip. In [13], a mathematical model of skip motion using the Hamilton principle is developed and verified with the data obtained with the use of experimental machine. Hamilton's principle is also applied when modelling the motion of a lifting vessel in $[14,15]$. Similar mathematical modelling is carried out in [16]. However, the purpose of this work is to assess the effect of the lifting force on the oscillations of the lifting vessel. The case of emergency during the operation of skip is considered in [17]. In particular, the author defines braking parameters that will not lead to critical consequences. The work [18] is devoted to the study of the relationship between the slipping of the hoisting rope during the operation of the hoisting machine and the tension force of the rope. In the article [19], a mathematical model of the skip motion is developed and the analysis of accounting for various parameters on the nature of the oscillations of the studied system is conducted. The article [20] analyzes the skip lift in order to optimize its operation. Also, in this article a new lifting scheme with two lifting friction sheaves is proposed. Modelling of the dynamic behavior of the skip hoist is also described in [21].

After analyzing the literature, one can see that there are many gaps in modeling skip dynamics. Almost all authors of works on this problem agree that the study of skip dynamics is a very difficult task. This is also evidenced by the number of works devoted to this topic and the variety of solution approaches.

This paper provides an analytical solution to the problem of determining the forces arising from the interaction of skip with guides problem using a motion smoothness monitoring system installed on skips of one of the JSC "Belaruskali" shafts.

\section{Equations of skip motion}

The problem of development of a mathematical model of skip movement under the influence of external and internal forces is considered. Gravity force is acting on skip with cargo at point $C$ (center of mass); forces $\bar{F}_{0}, \bar{F}_{1}, \bar{F}_{2}, \bar{F}_{3}, \bar{F}_{4}$ are acting at points $M_{0}$, $M_{1}, M_{2}, M_{3}, M_{4}$ respectively. $M_{0}$ is suspension point; $M_{1}\left(x_{1}, 0, z_{1}\right), M_{2}\left(-x_{1}, 0, z_{1}\right)$, $M_{3}\left(x_{3}, 0, z_{3}\right), M_{4}\left(-x_{3}, 0, z_{3}\right)$ are the contact points; $M_{5}\left(x_{5}, y_{5}, z_{5}\right), M_{6}\left(x_{6}, y_{6}, z_{6}\right)$ are positions of accelerometers of the monitoring system; $W_{i}$ are values of accelerations according to data coming from accelerometers. The sought values in this case are the forces $\bar{F}_{1}, \bar{F}_{2}, \bar{F}_{3}, \bar{F}_{4}$ of contact interaction of the skip with the guides. The values of the force interaction of skip with guides allow making conclusions about the values of elastic strain and the possibility of plastic strain occurrence in the guides. In addition, it is possible to make conclusions about the wear-out of individual elements of the shaft structure under multi-cycle load from the side of the lifting vessel using the interaction forces values. The values of elastic strain can signal an emergency. The values of plastic strain and mechanical wear-out can be an indicator of the need to replace individual links of guides.

Skip movement during lifting consists of translational motion with a given velocity $v(t)$ along $O Z$ axis of the $O X Y Z$ fixed coordinate system and five independent motions: two translational motions along $O X$ and $O Y$ axes and three rotations around $C X^{\prime}, C Y^{\prime}$, $C Z^{\prime}$ axes of the Koenig coordinate system [22] (Fig. 1). 

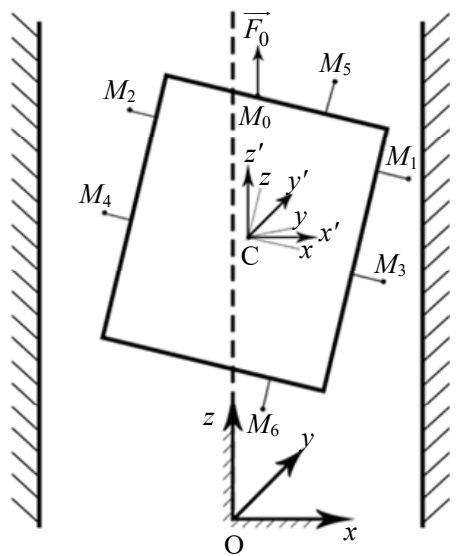

Fig. 1. Skip force action scheme.

Skip as an absolutely rigid body, with respect to the coordinate system moving translationally vertically with a velocity of $v(t)$, has 5 degrees of freedom and its relative motion under the action of forces $\overline{F_{i}}\left(\overline{F_{i x}}, \overline{F_{i y}}, 0\right), i=\overline{1,4}$ applied at points $M_{i}, i=\overline{1,4}$ can be described by equations [23]:

$$
\begin{aligned}
& M \cdot \bar{W}_{c}=\sum_{i=1}^{4} \bar{F}_{i}, \\
& \frac{d \bar{K}_{c}^{\prime}}{d t}=\sum_{i=1}^{4} \overline{C M}_{i} \cdot \bar{F}_{i} .
\end{aligned}
$$

Equations (1), (2) are vector records of center of mass motion theorem relative to $O X Y Z$ coordinate system and change of kinetic moment theorem relative to $C X^{\prime} Y^{\prime} Z^{\prime}$ coordinate system.

We assume that a skip with and without cargo is symmetrical relative to the vertical axis both in geometric and material sense.

We also note that directions of the corresponding axes of $C X^{\prime} Y^{\prime} Z^{\prime}$ coordinate systems and $C x y z$ differ little from each other due to small curvature of surfaces of the guides. Hence, skip moments of inertia included in $\bar{K}_{c}^{\prime}$ and coordinates of points $M_{i}$ in $C X^{\prime} Y^{\prime} Z^{\prime}$ coordinate system are replaced by constant values in $O x y z$ coordinate system.

We project (1) on the axes $O X$ and $O Y$ of a fixed coordinate system:

$$
\begin{aligned}
M \cdot \ddot{X}_{c} & =\sum_{i=1}^{4} F_{i x}, \\
M \cdot \ddot{Y}_{c} & =\sum_{i=1}^{4} F_{i y} .
\end{aligned}
$$

Since $\bar{K}_{c}^{\prime}=\left(I_{x} \dot{\varphi}_{x}, I_{y} \dot{\varphi}_{y}, I_{z} \dot{\varphi}_{z}\right), \overline{C M}_{i}=\left(x_{i}, 0, z_{i}\right)$, the equation (2) in projections on the Koenig coordinate system axis has form:

$$
\begin{gathered}
I_{x} \ddot{\varphi}_{x}=-z_{1}\left(F_{1 y}+F_{2 y}\right)-z_{3}\left(F_{3 y}+F_{4 y}\right), \\
I_{y} \ddot{\varphi}_{y}=z_{1}\left(F_{1 x}+F_{2 x}\right)+z_{3}\left(F_{3 x}+F_{4 x}\right),
\end{gathered}
$$




$$
I_{z} \ddot{\varphi}_{z}=x_{1}\left(F_{1 y}+F_{3 y}-F_{2 y}-F_{4 y}\right) .
$$

It is taken into account that $x_{2}=-x_{1}, x_{3}=x_{1}, x_{4}=-x_{1}, z_{2}=z_{1}, z_{4}=z_{3}$ due to the symmetry of the contact points location.

Equations (3) - (7) are approximate, since during derivation of this equations, the values of a higher order of smallness were neglected in comparison with $X_{c}, Y_{c}, \varphi_{x}, \varphi_{y}, \varphi_{z}$.

Now, having skip dynamics mathematical model, we can proceed to determining the force interaction of skip with guides using the acceleration data coming from the motion smoothness monitoring system.

\section{Determining the force effect on skip from the side of the guides}

The velocity $\bar{V}$ of any point $M$ of the skip relative to the fixed $O X Y Z$ coordinate system can be approximately found using formula [24]:

$$
\bar{V}=\overline{V_{c}}+\bar{\omega} \cdot \overline{C M}
$$

Here $\bar{\omega}=\left(\dot{\varphi}, \dot{\varphi}_{y}, \dot{\varphi}_{z}\right)$ is the angular velocity of $C x y z$ coordinate system relative to $C X^{\prime} Y^{\prime} Z^{\prime}$ coordinate system, and the vector $\overline{C M}$ in $C X^{\prime} Y^{\prime} Z^{\prime}$ coordinate system is replaced as it was done during deriving equation (5) - (7) by its constant value in $C x y z$ coordinate system.

After differentiation, we write equality (8) for points $M_{5}, M_{6}$ :

$$
\begin{gathered}
\overline{W_{5}}=\overline{W_{c}}+\varepsilon \cdot \overline{C M_{5}}, \\
\overline{W_{6}}=\overline{W_{c}}+\varepsilon \cdot \overline{C M_{6}}, \\
\bar{\varepsilon}=\left(\ddot{\varphi}_{x}, \ddot{\varphi}_{y}, \ddot{\varphi}_{z}\right) .
\end{gathered}
$$

Subtracting equality (9) from equality (10), we obtain:

$$
\overline{W_{6}}-\overline{W_{5}}=\bar{\varepsilon} \cdot \overline{M_{5}} \overline{M_{6}} .
$$

We project relation (9) on the fixed $O X, O Y$ axes and the equality (11) on axis of $C X^{\prime} Y^{\prime} Z^{\prime}$ coordinate system.

$$
\begin{aligned}
& W_{x 5}=W_{x c}+\ddot{\varphi}_{y} \cdot z_{5}-\ddot{\varphi}_{z} \cdot y_{5}, \\
& W_{y 5}=W_{y c}+\ddot{\varphi}_{z} \cdot x_{5}-\ddot{\varphi}_{x} \cdot z_{5}, \\
& W_{x 6}-W_{x 5}=\ddot{\varphi}_{y}\left(z_{6}-z_{5}\right)-\ddot{\varphi}_{z}\left(y_{6}-y_{5}\right), \\
& W_{y 6}-W_{y 5}=\ddot{\varphi}_{y}\left(x_{6}-x_{5}\right)-\ddot{\varphi}_{x}\left(z_{6}-z_{5}\right), \\
& W_{z 6}-W_{z 5}=\ddot{\varphi}_{x}\left(y_{6}-y_{5}\right)-\ddot{\varphi}_{y}\left(x_{6}-x_{5}\right) .
\end{aligned}
$$

Since $\left(\overline{W_{6}}-\overline{W_{5}}\right) \perp \overline{M_{5} M_{6}}$, then

$$
W_{z 6}-W_{z 5}=\frac{\left(W_{x 6}-W_{x 5}\right)\left(x_{6}-x_{5}\right)+\left(W_{y 6}-W_{y 5}\right)\left(y_{6}-y_{5}\right)}{z_{5}-z_{6}} .
$$


Now we express the quantities $\ddot{X}_{c}, \ddot{Y}_{c}, \ddot{\varphi}_{x}, \ddot{\varphi}_{y}, \ddot{\varphi}_{z}$ from equations (3)-(7) and substitute them into formulas (12). The obtained equalities can be considered as a system of linear equations with respect to $d_{i}(t), i=\overline{1,5}$.

$$
A \cdot\left(\begin{array}{l}
d_{1} \\
d_{2} \\
d_{3} \\
d_{4} \\
d_{5}
\end{array}\right)=\left(\begin{array}{l}
C_{1} \\
C_{2} \\
C_{3} \\
C_{4} \\
C_{5}
\end{array}\right) .
$$

Here:

$$
\begin{gathered}
C_{1}=M \cdot W_{x 5}, C_{2}=M \cdot\left(W_{x 6}-W_{x 5}\right), C_{3}=M \cdot W_{y 5}, \\
C_{4}=M \cdot\left(W_{y 6}-W_{y 5}\right), C_{5}=-M \cdot\left(W_{z 6}-W_{z 5}\right), \\
A=\left(\begin{array}{ccccc}
1+\frac{M}{I y} z_{1} \cdot z_{5} & 1+\frac{M}{I y} z_{3} \cdot z_{5} & 0 & 0 & -\frac{M}{I z} x_{1} \cdot y_{5} \\
\frac{M}{I y} z_{1}\left(z_{6}-z_{5}\right) & \frac{M}{I y} z_{3}\left(z_{6}-z_{5}\right) & 0 & 0 & -\frac{M}{I z} x_{1}\left(y_{6}-y_{5}\right) \\
0 & 0 & 1+\frac{M}{I z} z_{1} \cdot z_{5} & 1+\frac{M}{I x} z_{3} \cdot z_{5} & \frac{M}{I z} x_{1} \cdot x_{5} \\
0 & \frac{M}{I x} z_{1}\left(z_{6}-z_{5}\right) & \frac{M}{I x} z_{3}\left(z_{6}-z_{5}\right) & \frac{M}{I z} x_{1}\left(x_{6}-x_{5}\right) \\
\frac{M}{I y} z_{1}\left(x_{6}-x_{5}\right) & \frac{M}{I y} z_{3}\left(x_{6}-x_{5}\right) & \frac{M}{I x} z_{1}\left(y_{6}-y_{5}\right) & \frac{M}{I x} z_{3}\left(y_{6}-y_{5}\right) & 0 \\
d_{1}=F_{1 x}+F_{2 x}, \quad d_{2}=F_{3 x}+F_{4 x}, & d_{3}=F_{1 y}+F_{2 y}, d_{4}=F_{3 y}+F_{4 y}, d_{5}=F_{1 y}+F_{3 y}-F_{2 y}-F_{4 y} .
\end{array}\right.
\end{gathered}
$$

It is necessary to require that $\operatorname{det} A$ is not a small quantity to solve the system (13). This can be achieved by choice of a suitable sites for accelerometers installation.

We obtain the main force vector $\overline{F_{c}}$ and main moment $\overline{M_{c}}$ of the forces with which the skip acts on guides after solving system (13):

$$
\overline{F_{c}}=\left(d_{1}+d_{2}, d_{3}+d_{4}, 0\right), \overline{M_{c}}=\left(-z_{1} \cdot d_{3}+z_{3} \cdot d_{4}, z_{1} \cdot d_{1}+z_{3} \cdot d_{2}, x_{1} \cdot d_{5}\right) .
$$

The intensity of this force action is determined by the modules of vectors:

$$
\begin{aligned}
& F_{c}=\sqrt{\left(d_{1}+d_{2}\right)^{2}+\left(d_{3}+d_{4}\right)^{2}}, \\
& M_{c}=\sqrt{\left(z_{1} \cdot d_{3}+z_{3} \cdot d_{4}\right)^{2}+\left(z_{1} \cdot d_{1}+z_{3} \cdot d_{2}\right)^{2}+\left(x_{1} \cdot d_{4}\right)^{2}} .
\end{aligned}
$$

We move from forces $d_{i}(t)$ to impulses $S d_{i}(t), S C_{i}(t)$ in equation (13) in order to level out sharp changes in accelerations $\overline{W_{5}}, \overline{W_{6}}$ for the time $\tau$ which can be selected from the acceleration graphs of points $M_{5}, M_{6}$ :

$$
S d_{i}(t)=\int_{t}^{t+\tau} d_{i}(\theta) d \theta, S C_{i}(t)=\int_{t}^{t+\tau} C_{i}(\theta) d \theta, i=\overline{1,5} .
$$

We obtain formulas for the corresponding impulses instead of formulas (14), (15) after the transition from forces $d_{i}(t)$ to impulses $S d_{i}(t)$ : 


$$
\begin{aligned}
& \overline{S F_{c}}(t)=\left(S d_{1}+S d_{2}, S d_{3}+S d_{4}, 0\right), \\
& \overline{S M_{c}}(t)=\left(-\left(z_{1} \cdot S d_{3}+z_{3} \cdot S d_{4}\right), z_{1} \cdot S d_{1}+z_{3} \cdot S d_{2}, x_{1} \cdot S d_{5}\right), \\
& S F_{c}=\sqrt{\left(S d_{1}+S d_{2}\right)^{2}+\left(S d_{3}+S d_{4}\right)^{2}}, \\
& S M_{c}=\sqrt{\left(z_{1} \cdot S d_{3}+z_{3} \cdot S d_{4}\right)^{2}+\left(z_{1} \cdot S d_{1}+z_{3} \cdot S d_{2}\right)^{2}+\left(x_{1} \cdot S d_{4}\right)^{2}} .
\end{aligned}
$$

The force effect on guides from the side of skip changes when the skip moves and this effect is fixed by functions $S F_{c}(t), S M_{c}(t)$. The greatest impact on the skip along the entire path of its movement during ascent or descent takes place with a maximum of these functions. In other words, if $S F_{c}\left(t_{1}\right)$ and $S M_{c}\left(t_{2}\right)$ are the maximum values of the functions $S F_{c}(t), S M_{c}(t)$ at time instants $t_{1}$ and $t_{2}$, then at $t \in\left[t_{1}, t_{1}+\tau\right]$ and $t \in\left[t_{2}, t_{2}+\tau\right]$ the skip acts on guides more strongly than on any other interval of length $\tau$.

Now we can calculate the path passed by the skip mass center at time $t_{1}+\tau$ and $t_{2}+\tau$ using the known value of its vertical velocity. As a result we obtain the vertical coordinates $Z_{c}\left(t_{1}+\frac{\tau}{2}\right), Z_{c}\left(t_{2}+\frac{\tau}{2}\right)$ of the point $\mathrm{C}$. Then, the cause of occurrence of surge in impulses $S F_{c}(t), S M_{c}(t)$ is in the intervals of $Z_{c}\left(t_{1}+\frac{\tau}{2}\right) \pm 10 \mathrm{~m}, Z_{c}\left(t_{2}+\frac{\tau}{2}\right) \pm 10 \mathrm{~m}$.

Thus, for each set of acceleration values a system of linear equations (13) is solved and the sought values are determined.

The figures further show the graphs of the force vector module and the moment vector module (Figs. 6 and 7) as well as the graphs of the impulse and angular momentum (Figs. 8 and 9) for one lifting depending on time in accordance with the acceleration data received from the motion smoothness monitoring system installed on one of the mine shafts of JSC Belaruskali.

In Figs. 2-5, green and orange lines are the deviation of guides of corresponding direction in accordance with profiling data of guides of the considered mine shaft.

We exactly mark the positions of the skip where skip force effect on guides is much higher than at other positions according to graphs shown in Figs. 6 - 9 .

Orange lines in Figs. 6 and 7 show the deviation modulus of the guides $\sqrt{\left(X_{1 i}+X_{2 i}\right)^{2}+\left(Y_{1 i}+Y_{2 i}\right)^{2}}$, where $X_{1 i}, Y_{1 i}, X_{2 i}, Y_{2 i}$ are deviations in the frontal and lateral direction of the $i$-th link of the $1^{\text {st }}$ and $2^{\text {nd }}$ guide.

The processing of the profiling data results, motion smoothness monitoring system data and the model calculations shows that there is no direct correspondence between guides deviations and the forces values in the sense that in places where a significant deviation of the guide is observed, there is not necessarily a surge in the same place. A surge in force may occur some time after the guide deviation.

So, Figs. 2 and 3 show some direct correlation between surges of force and deviations of guides. In Figs. 4 and 5, this correlation is less noticeable. One of the reasons for this effect is that a surge of forces corresponding to the impact occurs after a complete selection of the stroke of roller springs. Only two springs presence in the case of frontal forces $d_{1}$, $d_{2}$ (see Figs. 2 and 3) while in case of lateral forces $d_{3}, d_{4}$ (see Figs. 4 and 5), there are four springs. Thus, when considering the total forces along $O y$ axis, it should be borne in mind that the possible impact is caused by larger deviations than along $O x$ axis. 


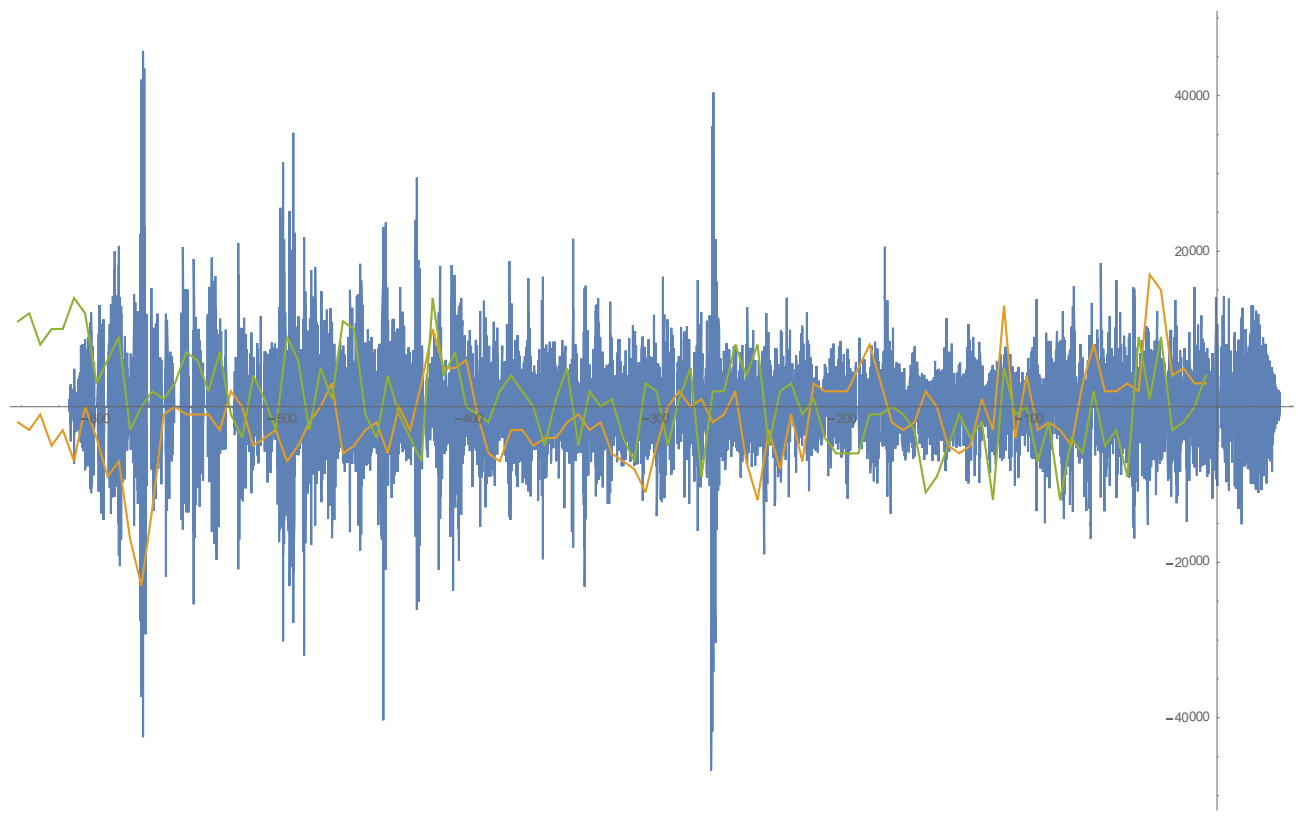

Fig. 2. The graph of force $b_{1}=F_{1 x}+F_{2 x}$.

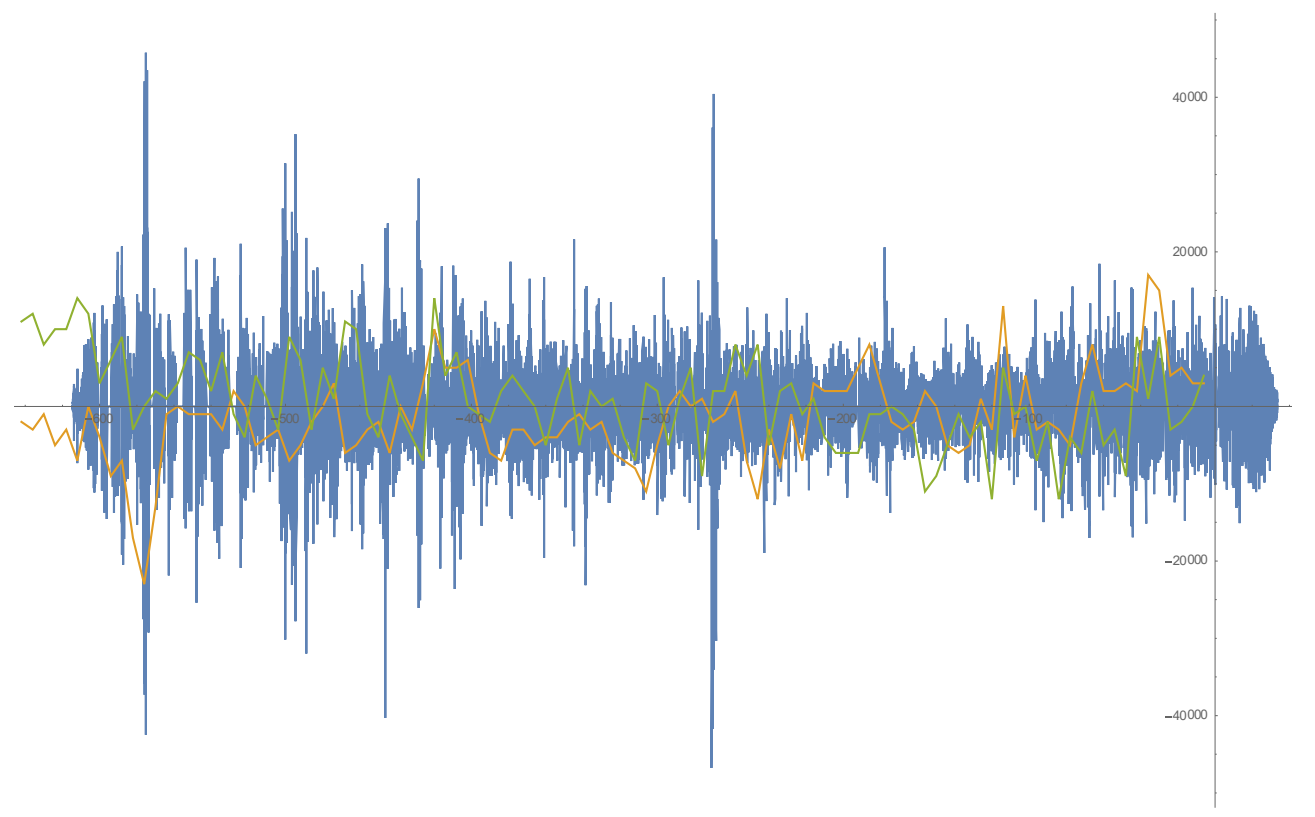

Fig. 3. The graph of force $b_{2}=F_{3 x}+F_{4 x}$. 


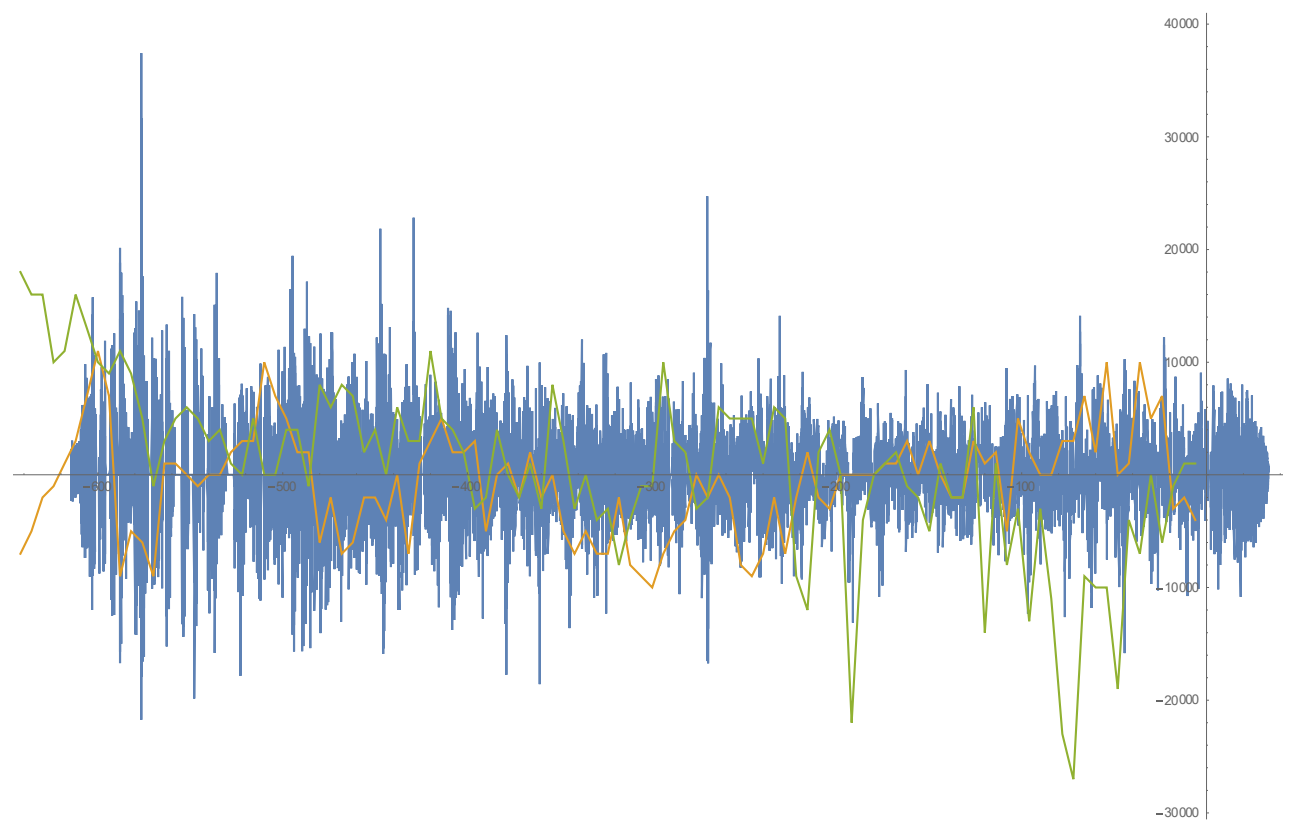

Fig. 4. The graph of force $b_{3}=F_{1 y}+F_{2 y}$.

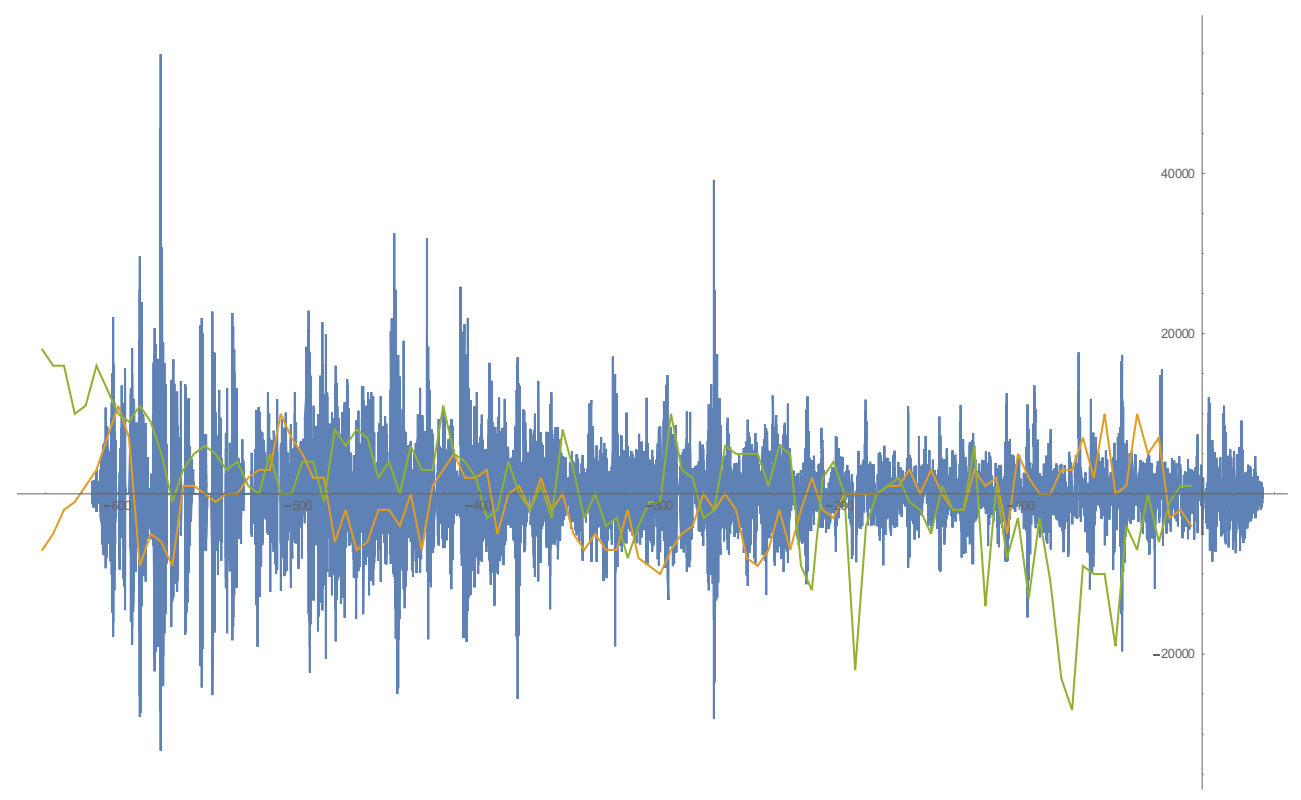

Fig. 5. The graph of force $b_{4}=F_{3 y}+F_{4 y}$. 


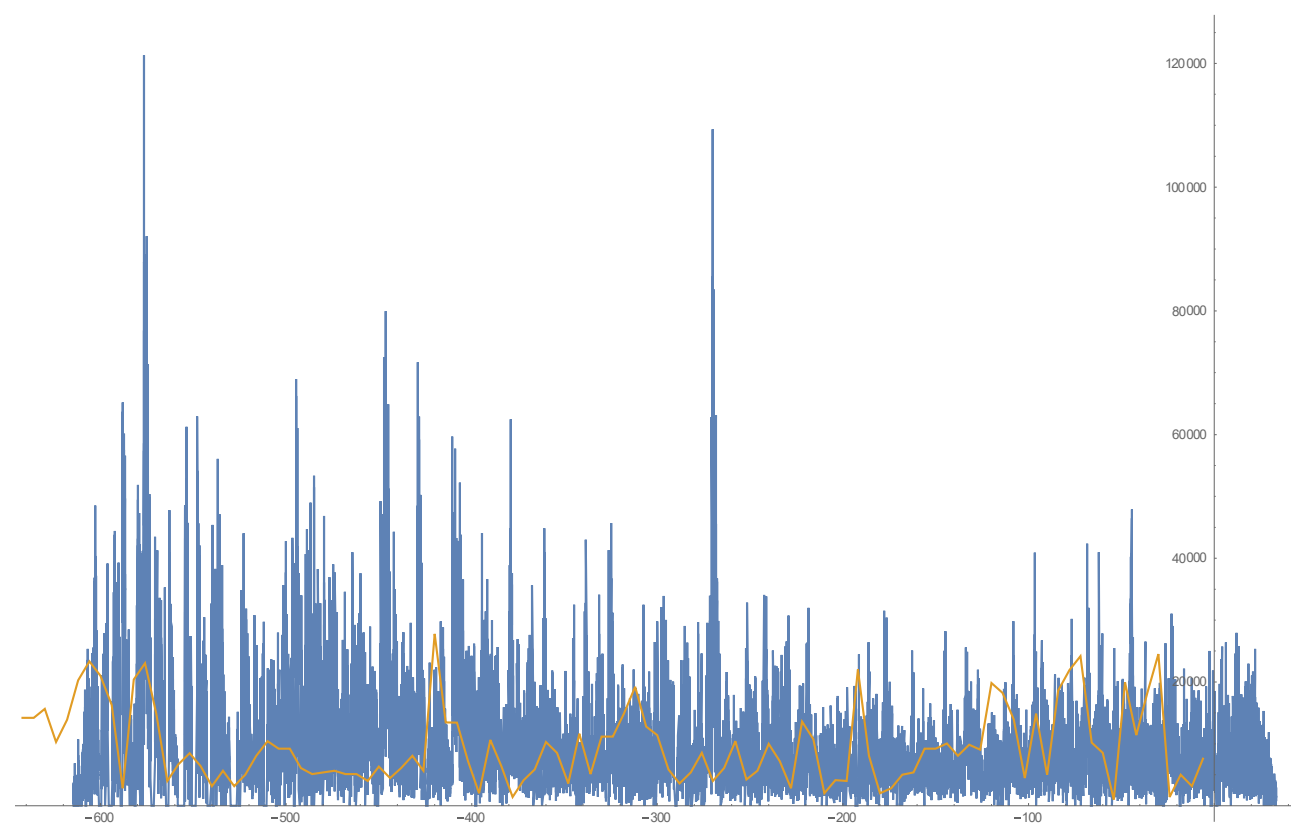

Fig. 6. Force vector module graph $\overline{F_{c}}$.

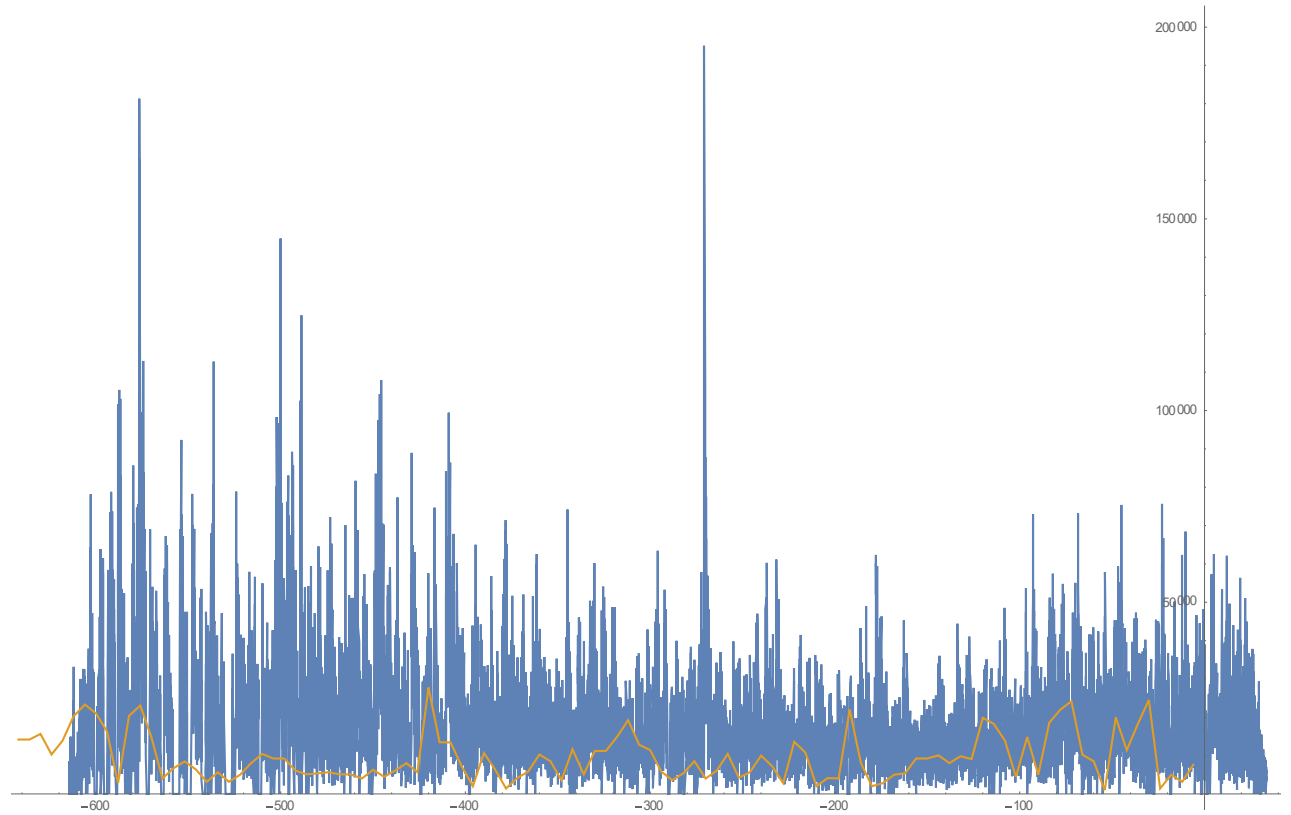

Fig. 7. Moment vector module graph $\overline{M_{c}}$. 


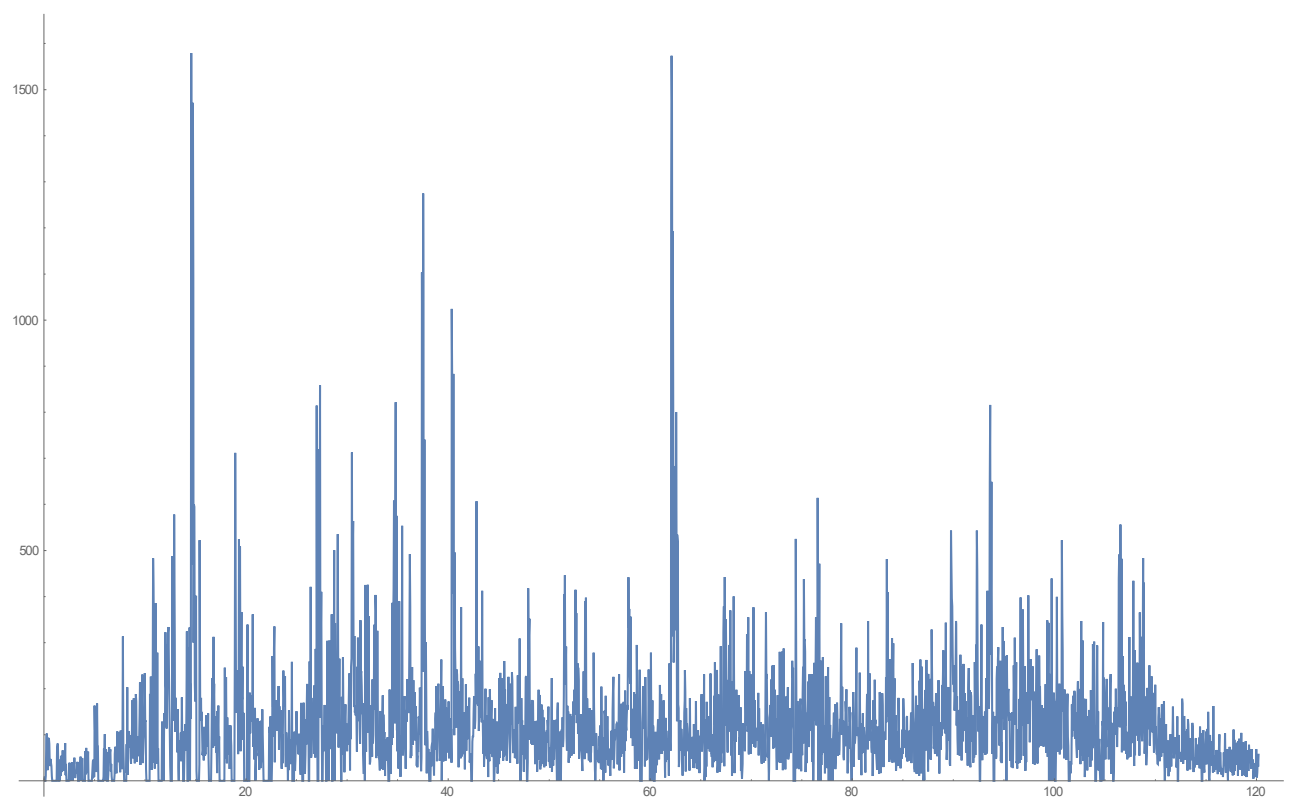

Fig. 8. Impulse graph $S F_{c}(t)$ at $\tau=0.04$

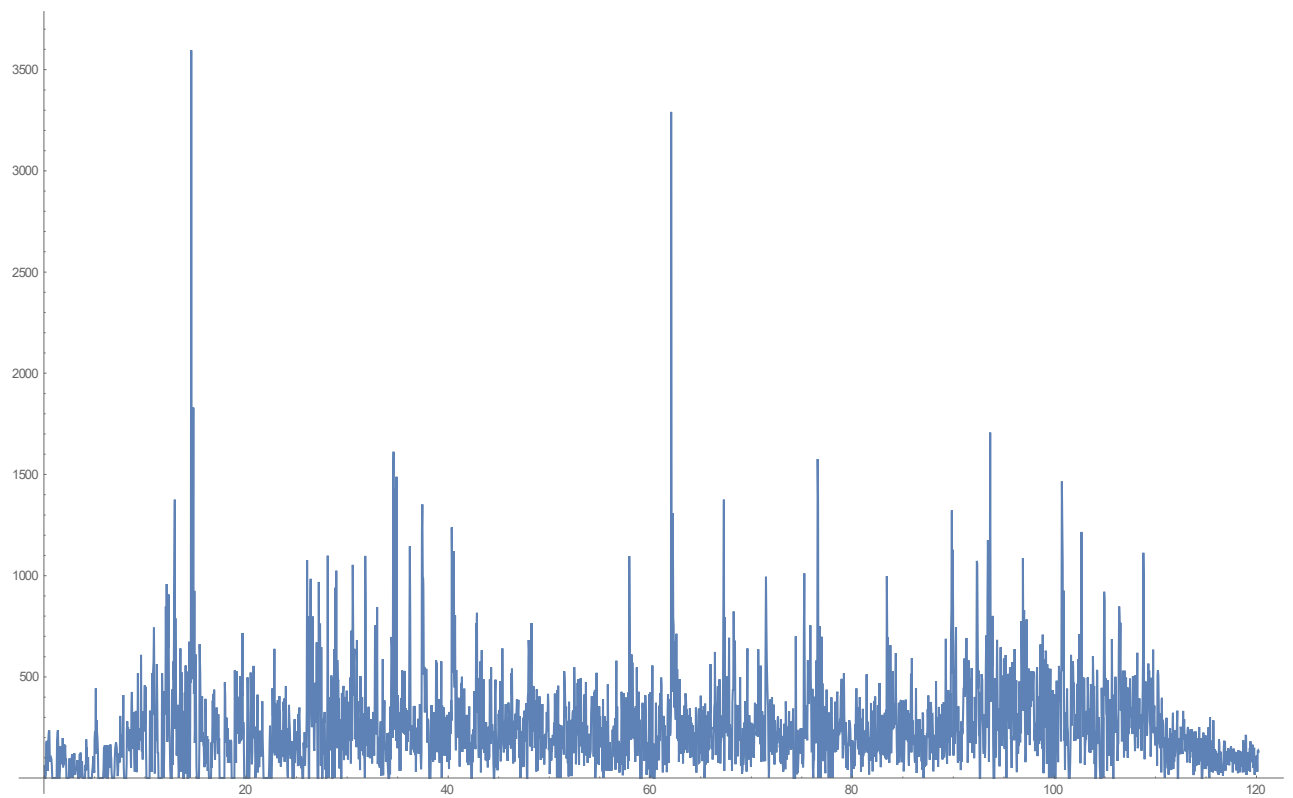

Fig. 9. Moment of impulse graph $S M_{c}(t)$ at $\tau=0.04$.

It should be noted that reliability of results may be evidenced by analysis of sections of the greatest surge in forces. The first section of a significant surge of forces (located at the beginning of the ascent) corresponds to the largest deflection of the guides in the frontal direction. The second section of a significant surge of forces (in the middle of the ascent) 
corresponds to the intersection of the rising skip and counterweight skip which is in good agreement with the results obtained in $[3,4]$.

\section{Conclusions}

An analytical solution to the problem of finding the force effect of skip on guides during its movement in mine shaft is proposed. The values of force effect $d_{i}, i=\overline{1,5}$ have been determined using the acceleration values of two skip points obtained with the help of accelerometers of motion smoothness monitoring system. An integral transition from forces to impulse actions has been performed in order to reduce random effects. The results of the solution based on considered model have a certain correlation with profiling data.

It is possible to make conclusions about the section of lifting where an impact on the guides occurs when there is a set of statistics of the force effect surges. This technique can be used in a skip motion monitoring system to prevent emergencies.

This work was conducted within the state research program "Convergence-2020" (State registration No. 20161712). Task No. 1.8.01.1 "Development of mathematical models and methods for solving new classes of boundary value problems of continuum mechanics as applied to current contemporary problems of science and technology".

\section{References}

1. Kuznetsov, N.K., Eliseev, S.V., \& Perelygina, A.Y. (2018). Reduction of Dynamic Loads in Mine Lifting Installations. Journal of Physics: Conference Series, (944), 012070. https://doi.org/10.1088/1742-6596/944/1/012070

2. Samusia, V., Iliina, I., \& Iliina, S. (2016). Computer modeling and investigation of dynamics of system "vessel-reinforcement"in shafts with broken geometry. Vestnik Permckogo Natsional'nogo Issledovatel'skogo Politekhnicheskogo Universiteta. Geologiya. Neftegazovoe i Gornoe Delo, (20), 277-285. https://doi.org/10.15593/2224-9923/2016.20.8

3. Wu, R., Zhu, Z., \& Cao, G. (2015). Computational Fluid Dynamics Modeling of Rope-Guided Conveyances in Two Typical Kinds of Shaft Layouts. PLOS ONE, 10(2), e0118268. https://doi.org/10.1371/journal.pone.0118268

4. Wu, R., Zhu, Z., Chen, G., \& Cao, G., \& Li, W. (2014). Simulation of the lateral oscillation of rope-guided conveyance based on fluid-structure interaction. Journal of Vibroengineering, 16(3), 1555-1563.

5. Pershin, V., Kopytov, A., \& Wetti, A. (2019). Research in the Impact of Dynamic Loads for the Development of Pentice Designs when Sinking Skip Shafts. E3S Web of Conferences, (105), 01056. https://doi.org/10.1051/e3sconf/201910501056

6. Wolny, S., \& Matachowski, F. (2010). Analysis of loads and stresses in structural elements of hoisting installations in mines. Engineering Transactions, 58(3-4), 153-174.

7. Wang, D., Zhang, D., \& Ge, S. (2013). Determination of fretting parameters of hoisting rope in coalmine and fretting-fatigue behavior of steel wires. Industrial Lubrication and Tribology, 65(6), 436-448. http://dx.doi.org/10.1108/ILT-03-2011-0021

8. Chouairi1, A., Ghorba1, M. El, \& Benali1, A. (2012). Analytical approach of availability and maintainability for structural lifting cables using reliability-based optimization. International Journal of Engineering and Science, 1(1), 21-30.

9. Chaplin, C.R. (1994). Hoisting Ropes for Drum Winders - The Mechanics of Degradation. Institutions of Mining Engineers, 76(877), 213-219.

10. Guo, Y., Zhang, D., Zhang, X., Wang, S., \& Ma, W. (2020). Experimental Study on the Nonlinear Dynamic Characteristics of Wire Rope under Periodic Excitation in a Friction Hoist. Shock and Vibration, 2020, 1-14. https://doi.org/10.1155/2020/8506016 
11. Guo, Y., Zhang, D., Zhang, X., Wang, D., \& Wang, S. (2020). A New Transmission Theory of "Global Dynamic Wrap Angle" for Friction Hoist Combining Suspended and Wrapped Wire Rope. Applied Sciences, 10(4), 1305. https://doi.org/10.3390/app10041305

12. Zhang, D., Guo, Y., Feng, C., \& Liu, Y. (2016). Dynamic creeping behaviors between hoisting rope and friction lining in friction transmission. Journal of Vibroengineering, 18(8), 5010-5028. https://doi.org/10.21595/jve.2016.17555

13. Bao, J., Zhang, P., \& Zhu, C. (2015). Dynamic Analysis of Flexible Hoisting Rope with Time-

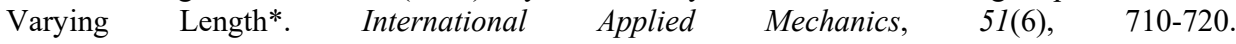
http://dx.doi.org/10.1007/s10778-015-0729-z

14. Wang, G., Xiao, X., \& Liu, Y. (2019). Dynamic Modeling and Analysis of a Mine Hoisting System with Constant Length and Variable Length. Mathematical Problems in Engineering, 2019, 1-12. https://doi.org/10.1155/2019/4185362

15. Wu, J., \& Kou, Z. (2016). Theoretical coupling longitudinal-transverse model and experimental verification of transverse vibration of rope for multi-rope friction hoisting system. International Journal of Coal Science \& Technology, 3(1), 77-84. https://doi.org/10.1007/s40789-016-0110-9

16. Yao, J., \& Xiao, X. (2016). Effect of Hoisting Load on Transverse Vibration of Hoisting Catenaries in Floor Type Multirope Friction Mine Hoists. Shock and Vibration, 2016(9), 1-15. http://dx.doi.org/10.1155/2016/8598749

17. Wolny, S. (2017). Emergency Braking of a Mine Hoist in the Context of the Braking System Selection. Archives of Mininig Sciences, 62(1), 45-54.

18. Huang, T., Tan, J., Xue, S., \& Shi, L. (2019). Research on The Influence of Rope Jumping on The Tension of Multi-layer Winding Wire Ropes in Super Deep Mine Hoisting Machine. IOP Conference Series: Materials Science and Engineering, (563), 032032. https://doi.org/10.1088/1757-899x/563/3/032032

19. Vladić, J. (2015). Theoretical and experimental analysis of mine elevator dynamic characteristics. Tehnicki Vjesnik-Technical Gazette, 22(4), 1011-1020. https://doi.org/10.17559/tv20150107175453

20. Ilin, S., Adorska, L., Samusia, V., Kolosov, D., \& Ilina, I. (2019). Conceptual bases of intensification of mining operations in mines of Ukraine based on monitoring and condition management of mine hoisting systems. E3S Web of Conferences, (109), 00030. https://doi.org/10.1051/e3sconf/201910900030

21. Cao, G., Cai, X., Wang, N., Peng, W., \& Li, J. (2017). Dynamic Response of Parallel Hoisting System under Drive Deviation between Ropes with Time-Varying Length. Shock and Vibration, 2017, 1-10. https://doi.org/10.1155/2017/6837697

22. Lidov, M.L. (2010). Kurs lektsiy po teoreticheskoy mekhanike. Moskva Fizmatlit, 497.

23. Vyar'vil'skaya, O.N., Medvedev, D.G., Savenkov, V.A., \& Savchuk, V.P. (2006). Teoreticheskaya mekhanika. Minsk: Belorusskiy Gosudarstvennyy Universitet, 287.

24. Yablonskiy, A.A, \& Nikiforova, V.M. (1966). Kurs tereticheskoy mekhaniki. Moskva: Vysshaya Shkola, 355. 